\title{
A Mathematical Model and Analytical Solution for the Fixation of Bacteria in Biogrout
}

\author{
W. K. van Wijngaarden • F. J. Vermolen • \\ G. A. M. van Meurs • C. Vuik
}

Received: 21 July 2011 / Accepted: 30 December 2011 / Published online: 27 January 2012

(C) The Author(s) 2012. This article is published with open access at Springerlink.com

\begin{abstract}
Biogrout is a new method for soil reinforcement, which is based on microbialinduced carbonate precipitation. Bacteria and reactants are flushed through the soil, resulting in calcium carbonate precipitation and consequent soil reinforcement. Bacteria are crucially important in the Biogrout process since they catalyse the reaction. Hence, to control the process, it is essential to know where the bacteria are located. The bacteria are possibly in suspension but can also be adsorbed or fixated on the matrix of the porous structure. In this article, a model is derived for the placement of bacteria. The model contains three phases of bacteria: bacteria in suspension, adsorbed bacteria and fixed bacteria. An analytical solution is derived for instantaneous reactions between these three phases. The analytical solution is compared to numerical simulations for finite reaction rates. For the numerical simulations the standard Galerkin Finite Element Method is used.
\end{abstract}

Keywords Biogrout - Transport of bacteria - Microbial-induced carbonate precipitation . Soil improvement · Analytical solution

\section{List of symbols}

C Normalized concentration of suspended bacteria [1]

$C^{\text {adsorbed }}$ Normalized concentration of (temporarily and permanently) adsorbed bacteria [1]

$\bar{C} \quad$ Normalized concentration of temporarily adsorbed bacteria [1]

$S \quad$ Normalized concentration of fixated bacteria [1]

W. K. van Wijngaarden · F. J. Vermolen · C. Vuik

Delft Institute of Applied Mathematics, Delft University of Technology,

Mekelweg 4, 2628 CD Delft, The Netherlands

W. K. van Wijngaarden $(\varangle)$. G. A. M. van Meurs

Deltares, Unit Geo Engineering, Stieltjesweg 2, 2628 CK Delft, The Netherlands

e-mail: miranda_v_rossum@hotmail.com; Miranda.vanWijngaarden@Deltares.nl 


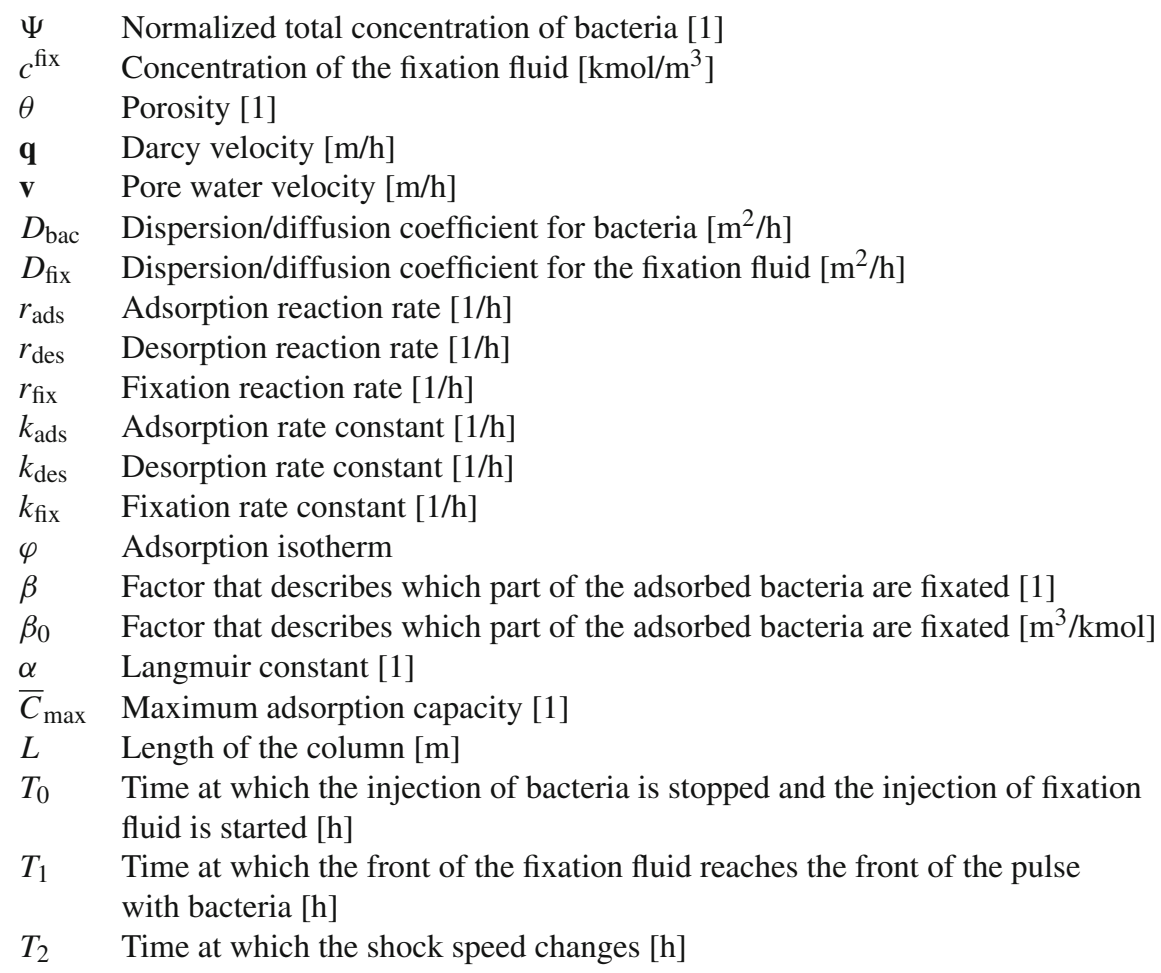

\section{Introduction}

\subsection{Technological Perspective}

The mechanical properties of soil (cohesion, friction, stiffness and permeability) are essential for engineering constructions. Nowadays, several techniques are developed, which change the soil properties according to technological demands. This is done by stimulating biochemical processes in situ (DeJong et al. 2010; Ivanov et al. 2008; Van Meurs et al. 2006). Biogrout is one of these techniques, which is based on microbial-induced carbonate precipitation (MICP).

Several researchers have shown that MICP can be used to improve the mechanical properties of porous materials (Bang et al. 2001; Bachmeier et al. 2002; Nemati et al. 2003; DeJong et al. 2006; Whiffin et al. 2007). Some examples of applications are

- prevention of liquefaction (Ruyt et al. 2009; DeJong et al. 2010);

- bore hole stabilization (Star et al. 2011);

- slope stabilization (DeJong et al. 2010);

- stabilization of railroad tracks (Van Paassen 2009);

- reinforcement of calcarenite room and pillar mines (Van Paassen et al. 2008).

This motivates the research on Biogrout.

The Biogrout process has been studied for a couple of years (Whiffin 2004; Whiffin et al. 2007; Van Paassen 2009; Van Paassen et al. 2009a,b, 2010; Harkes et al. 2010; Van Wijngaarden et al. 2010, 2011), in which the last two mentioned studies are computational. 


\subsection{The Biochemical Processes in Biogrout}

Biogrout is based on MICP. In this article, we focus on the Sporosarcina pasteurii bacteria. These bacteria contain the enzyme urease, that provides the hydrolysis of urea $\left(\mathrm{CO}\left(\mathrm{NH}_{2}\right)_{2}\right)$. The reaction equation for the hydrolysis of urea is given by (see Whiffin et al. 2007)

$$
\mathrm{CO}\left(\mathrm{NH}_{2}\right)_{2}(\mathrm{aq})+2 \mathrm{H}_{2} \mathrm{O}(\mathrm{l}) \stackrel{\text { bacteria }}{\longrightarrow} 2 \mathrm{NH}_{4}{ }^{+}(\mathrm{aq})+\mathrm{CO}_{3}{ }^{2-}(\mathrm{aq}) .
$$

The products of this reaction are carbonate $\left(\mathrm{CO}_{3}{ }^{2-}\right)$ and the by-product ammonium $\left(\mathrm{NH}_{4}{ }^{+}\right)$. In the presence of calcium ions $\left(\mathrm{Ca}^{2+}\right)$ and if the solution is oversaturated, the calcium and carbonate ions precipitate as calcium carbonate $\left(\mathrm{CaCO}_{3}\right)$. This happens in several steps, depending on the $\mathrm{pH}$. The overall precipitation reaction is given by (see also Whiffin et al. 2007)

$$
\mathrm{Ca}^{2+}(\mathrm{aq})+\mathrm{CO}_{3}{ }^{2-}(\mathrm{aq}) \rightarrow \mathrm{CaCO}_{3}(\mathrm{~s}) .
$$

Combining the hydrolysis reaction equation (1) and the precipitation reaction equation (2) gives the overall Biogrout reaction equation:

$$
\mathrm{CO}\left(\mathrm{NH}_{2}\right)_{2}(\mathrm{aq})+\mathrm{Ca}^{2+}(\mathrm{aq})+2 \mathrm{H}_{2} \mathrm{O}(\mathrm{l}) \rightarrow 2 \mathrm{NH}_{4}{ }^{+}(\mathrm{aq})+\mathrm{CaCO}_{3}(\mathrm{~s}) .
$$

When applying Biogrout, first the bacteria are cultivated. Subsequently, the bacteria are injected into the subsoil and transported by water flow to the location where strengthening is required. The bacterial suspension is directly followed by a fixation fluid, which is a solution with high salinity. As a consequence of the retardation of the bacteria, the fixation fluid will overtake the weakly adsorbed bacteria and strongly fix them to the soil particles (Harkes et al. 2010). This will result into a rather homogeneous distribution of bacteria. After the placement of the bacteria, the urea and calcium chloride $\left(\mathrm{CaCl}_{2}\right)$ solution is supplied (Whiffin et al. 2007). Due to the calcium chloride, this solution has a high salinity and will therefore also act as a fixation fluid. The bacteria provide the hydrolysis of urea and the calcium and carbonate ions precipitate as calcium carbonate. The calcium carbonate crystals form bridges between the sand grains, thereby increasing the strength and stiffness of the soil. The by-product ammonium chloride $\left(\mathrm{NH}_{4} \mathrm{Cl}\right)$ needs to be removed. The bacteria and reactants are not injected at the same time to prevent clogging and crystal accumulation around the injection point(s). The procedure, in which the bacteria are first injected and only then followed by the injection of the reactants, also results into a more homogeneous distribution of calcium carbonate.

\subsection{Transport of Bacteria}

Since the bacteria provide the hydrolysis of urea, they are crucial in the Biogrout process. The reaction rate increases with an increasing bacterial concentration and urease activity. Further, if no bacterium is present, no carbonate is formed and consequently no calcium carbonate appears. Therefore, it is essential to know where the bacteria are located in the aquifer.

When modelling bacterial transport, it is not sufficient to consider advection and dispersion only. Adsorption and desorption are important phenomena as well, but also the pore size of the matrix, the size of the microorganisms, filtration and elimination (Matthess et al. 1981, 1988; Fontes et al. 1991; Foppen et al. 2006), ionic strength of the ground water (Fontes et al. 1991; Foppen et al. 2006), systematic (chemotaxis) and random (tumbling) motion of bacteria (Yavuz Corapcioglu et al. 1984), residence time (Johnson et al. 1995), decay and 
growth (Yavuz Corapcioglu et al. 1984; Foppen et al. 2006) effect the (rate of) transport of microorganisms.

Hornberger et al. (1992), Johnson et al. (1995) and Tan et al. (1994) provide various models that consider several of these phenomena and compare the model results with experimental results.

\subsection{Scope of This Article}

In Van Wijngaarden et al. (2010, 2011), the study focusses on modelling the transport of the reactants, assuming a homogeneous distribution of bacteria. The present study is devoted to the transport, adsorption and fixation of the injected bacteria. In Sect. 2, a model is derived for the placement of bacteria. Further, initial and boundary conditions are given. In Sect. 3, the analytical solution for a simplified version of the model equations, described in Sect. 2, is presented. In Sect. 3, the Numerical Methods to solve the model equations are described. In Sect. 4, the results are displayed and a comparison is made between the analytical solution and the numerical solutions. In the last section, some conclusions and a discussion can be found.

\section{Mathematical Model}

\subsection{Derivation of the Model Equations}

First we present the general equation for the transport of bacteria in a fully saturated porous medium, as in for example, Tan et al. (1994):

$$
\frac{\partial(\theta C)}{\partial t}+\frac{\partial\left(\theta C^{\text {adsorbed }}\right)}{\partial t}=\nabla \cdot\left(D_{\mathrm{bac}} \theta \nabla C\right)-\nabla \cdot(\mathbf{q} C) .
$$

In this equation, $\theta$ is the porosity, $C$ is the bacterial concentration in suspension, $C$ adsorbed is the imaginary concentration that would result if the attached bacteria were to be resuspended in a solution volume equivalent to that of the surrounding water. Note that in literature, $C^{\text {adsorbed }}$ is frequently expressed in units of milligrams per kilogram, see for example, Zheng and Bennett (1995). Here, $C^{\text {adsorbed }}$ has the same unit as $C$. Further, $D_{\text {bac }}$ is the dispersion coefficient of bacteria in suspension and $\mathbf{q}$ is the Darcy velocity, which relates to the pore water flow velocity $\mathbf{v}$ as

$$
\mathbf{q}=\mathbf{v} \theta
$$

The terms at the left-hand side in Eq. 4 are the accumulation terms for the suspended and adsorbed bacteria. The first term at the right-hand side accounts for dispersion and the last term is the advection term. Since bacterial growth and decay are processes with a large time scale we neglect them. Further, we assume bacterial movement to be determined by flow only, which means that their systematic movement is neglected.

In the case of an equilibrium-controlled adsorption, $C^{\text {adsorbed }}$ tends to the equilibrium $\varphi(C)$, where $\varphi$ is an adsorption isotherm, which depends on the concentration of bacterial cells in suspension $(C)$ and also possibly depends on properties of the microorganisms, the porous medium and the pH. To be able to calculate $C$ and $C^{\text {adsorbed }}$ separately, Eq. 4 is split into two equations: 


$$
\begin{aligned}
\frac{\partial(\theta C)}{\partial t} & =\nabla \cdot\left(D_{\mathrm{bac}} \theta \nabla C\right)-\nabla \cdot(\mathbf{q} C)-\theta r_{\mathrm{ads}}+\theta r_{\mathrm{des}}, \\
\frac{\partial\left(\theta C^{\text {adsorbed }}\right)}{\partial t} & =\theta r_{\mathrm{ads}}-\theta r_{\mathrm{des}},
\end{aligned}
$$

where

$$
\begin{aligned}
& r_{\mathrm{ads}}=k_{\mathrm{ads}}\left(\varphi(C)-C^{\text {adsorbed }}\right)_{+}, \\
& r_{\mathrm{des}}=k_{\mathrm{des}}\left(C^{\text {adsorbed }}-\varphi(C)\right)_{+} .
\end{aligned}
$$

The reaction $r_{\text {ads }}$ is the adsorption reaction, $r_{\mathrm{des}}$ is the desorption reaction, $k_{\mathrm{ads}}$ and $k_{\mathrm{des}}$ are, respectively, the adsorption and desorption rate constants. The notation $(\cdot)_{+}$considers the positive part of an expression and has been defined as $(\cdot)_{+}:=\max (0, \cdot)$. Equations 8 and 9 account for the difference in desorption and adsorption rate. If there are no bacteria in suspension, no bacteria adsorb onto the matrix of the aquifer, therefore $\varphi(0)=0$. The number of bacteria that adsorb increases with the number of bacteria in suspension, hence $\varphi^{\prime}(C)>0$ and $\varphi(C)>0$. It is also assumed that $\varphi^{\prime \prime}(C)<0$ and $\lim _{C \rightarrow \infty} \varphi^{\prime}(C)=0$, which implies that the adsorption rate decreases as adsorption proceeds. This is a logical consequence from the fact that a higher number of adsorbed bacteria gives a lower number of free adsorption sites.

In the Biogrout process, the bacterial suspension is directly followed by a fixation fluid, which is a solution with a high salinity. This fixation fluid will overtake the weakly adsorbed bacteria and strongly fix them onto the solid matrix. In order to model this, $C^{\text {adsorbed }}$ is split up into a temporarily adsorbed part $\bar{C}$ and a permanently adsorbed, or fixed, part $S$ :

$$
C^{\text {adsorbed }}=\bar{C}+S \text {. }
$$

In the case of an equilibrium, the concentration of temporarily adsorbed bacteria $\bar{C}$ is given by $\bar{C}=(1-\beta) \varphi(C)$ and, since $S$ is the concentration of permanently adsorbed bacteria, which can not decrease, the following equilibrium holds: $S(\mathbf{x}, t)=\max _{0 \leq \bar{t} \leq t}\{\beta \varphi(C(\mathbf{x}, \bar{t}))\}$. From this equation, it follows that, for a constant $C, S=\beta \varphi(C)$. The fraction $\beta$ ranges between 0 and 1 , where the value depends on the concentration of the fixation fluid and it may also depend on, for example, properties of the microorganisms, the $\mathrm{pH}$ and the porous medium.

Substituting relation (10) into Eqs. 7-9, gives the following equations for the adsorbed bacteria:

$$
\begin{aligned}
\frac{\partial(\theta(\bar{C}+S))}{\partial t} & =\theta r_{\mathrm{ads}}-\theta r_{\mathrm{des}}, \\
r_{\mathrm{ads}} & =k_{\mathrm{ads}}(\varphi(C)-(\bar{C}+S))_{+} \\
r_{\mathrm{des}} & =k_{\mathrm{des}}(\bar{C}+S-\varphi(C))_{+} \\
& =k_{\mathrm{des}}((\bar{C}-(1-\beta) \varphi(C))+(S-\beta \varphi(C)))_{+} .
\end{aligned}
$$

Next, we show that Eq. 13 needs to be adjusted. According to this equation, both the difference between $\bar{C}$ and its equilibrium and the difference between $S$ and its equilibrium, are driving forces for desorption. Next, consider the situation $\bar{C}+S>\varphi(C), \bar{C}<(1-\beta) \varphi(C)$ and $S>\beta \varphi(C)$, which can happen if $C$ (and hence $\beta \varphi(C)$ ) is decreasing and if the adsorption rate $r_{\text {ads }}$ is not so high. Compared to the equilibrium $\beta \varphi(C)$, too many bacteria are adsorbed, and according to Eq. 13 there is a driving force for desorption. Concentration $S$ is the concentration of permanently adsorbed bacteria and these bacteria will not desorb again. This implies that the concentration temporarily adsorbed bacteria $\bar{C}$ will decrease. However, this concentration is already lower than its equilibrium $(1-\beta) \varphi(C)$. This means that the 
difference between $S$ and its equilibrium $\beta \varphi(C)$ will lead to extra desorption and this is not allowed. Therefore, the difference between $S$ and its equilibrium should only be taken into account if $S<\beta \varphi(C)$. In that case, it will diminish desorption. Hence, Eq. 13 is replaced with

$$
r_{\mathrm{des}}=k_{\mathrm{des}}\left((\bar{C}-(1-\beta) \varphi(C))+(S-\beta \varphi(C))_{-}\right)_{+},
$$

where the notation $(\cdot)_{-}$considers the negative part of an expression and is defined by $(\cdot)_{-}:=$ $\min (0, \cdot)$.

For the concentration of permanently adsorbed bacteria $S$, the following equation is used:

$$
\frac{\partial(\theta S)}{\partial t}=\theta r_{\text {fix }},
$$

where the fixation rate $r_{\text {fix }}$ is given by

$$
r_{\mathrm{fix}}=k_{\mathrm{fix}} \bar{C}(\beta \varphi(C)-S)_{+} .
$$

The constant $k_{\mathrm{fix}}$ is the fixation rate constant. The driving force for fixation is the difference between the concentration of fixated bacteria $S$ and its equilibrium $\beta \varphi(C)$, which is accounted for by the term $(\beta \varphi(C)-S)_{+}$. Only the positive part of this expression is taken into account, since $S$ is the concentration of permanently adsorbed bacteria, which can not decrease. If there are no adsorbed bacteria, they can not be fixated. If there are many adsorbed bacteria it is likely that fixation proceeds faster than in the case in which there are only a few adsorbed bacteria on the matrix. That is the reason why the fixation rate also contains a multiplication by $\bar{C}$. Note that the fixation of bacteria only occurs after adsorption.

From Eqs. 11 and 15, the following differential equation is found for the concentration temporarily adsorbed bacteria:

$$
\frac{\partial(\theta \bar{C})}{\partial t}=\theta r_{\mathrm{ads}}-\theta r_{\mathrm{des}}-\theta r_{\mathrm{fix}} .
$$

For the concentration of the fixation fluid $c^{\text {fix }}$, the following differential equation is used:

$$
\frac{\partial\left(\theta c^{\mathrm{fix}}\right)}{\partial t}=\nabla \cdot\left(D_{\mathrm{fix}} \theta \nabla c^{\mathrm{fix}}\right)-\nabla \cdot\left(\mathbf{q} c^{\mathrm{fix}}\right),
$$

where $D_{\text {fix }}$ is the dispersion coefficient of the fixation fluid.

To summarize, we solve the following system of equations for the transport of bacteria in a saturated porous medium, in combination with a fixation fluid.

$$
\begin{aligned}
\frac{\partial(\theta C)}{\partial t} & =\nabla \cdot\left(D_{\mathrm{bac}} \theta \nabla C\right)-\nabla \cdot(\mathbf{q} C)-\theta r_{\mathrm{ads}}+\theta r_{\mathrm{des}}, \\
\frac{\partial(\theta \bar{C})}{\partial t} & =\theta r_{\mathrm{ads}}-\theta r_{\mathrm{des}}-\theta r_{\mathrm{fix}}, \\
\frac{\partial(\theta S)}{\partial t} & =\theta r_{\mathrm{fix}}, \\
r_{\mathrm{ads}} & =k_{\mathrm{ads}}(\varphi(C)-(\bar{C}+S))_{+}, \\
r_{\mathrm{des}} & =k_{\mathrm{des}}\left((\bar{C}-(1-\beta) \varphi(C))+(S-\beta \varphi(C))_{-}\right)_{+}, \\
r_{\mathrm{fix}} & =k_{\mathrm{fix}} \bar{C}(\beta \varphi(C)-S)_{+}, \\
\frac{\partial\left(\theta c^{\mathrm{fix}}\right)}{\partial t} & =\nabla \cdot\left(D_{\mathrm{fix}} \theta \nabla c^{\mathrm{fix}}\right)-\nabla \cdot\left(\mathbf{q} c^{\mathrm{fix}}\right) .
\end{aligned}
$$




\subsection{Initial Conditions and Boundary Conditions}

For the concentration of suspended, adsorbed and fixed bacteria and for the concentration of the fixation fluid, the following initial conditions are chosen:

$$
C(x, 0)=\bar{C}(x, 0)=S(x, 0)=c^{\mathrm{fix}}(x, 0)=0 .
$$

At time $t=T_{0}$ the injection of bacteria is stopped and from then on the fixation fluid is injected. This results into the following boundary condition for the concentration of suspended bacteria:

$$
C(0, t)=\left\{\begin{array}{l}
1 \text { for } 0<t<T_{0}, \\
0 \text { for } t>T_{0},
\end{array}\right.
$$

and for the concentration of fixation fluid:

$$
c^{\mathrm{fix}}(0, t)= \begin{cases}0 & \text { for } 0<t<T_{0}, \\ 1 & \text { for } t>T_{0}\end{cases}
$$

\section{Analytical Solution and Numerical Methods}

In this section, the analytical solution for a simplified version of system (19)-(25) is derived. These simplifications have been made to be able to construct an analytical solution. Subsequently, a case study is presented for one particular adsorption isotherm. The model equations have also been solved numerically. The numerical strategy is described at the end of this section. The following simplifications have been made:

- Restriction to one dimension;

- The pore water velocity $v$ and the porosity $\theta$ are constant;

- Dispersion and diffusion are neglected: $D_{\mathrm{bac}}=D_{\mathrm{fix}}=0 \mathrm{~m}^{2} / \mathrm{h}$;

- For $\beta$ the following has been chosen: $\beta=\beta_{0} c^{\text {fix }}$, in which $\beta_{0}$ is a constant;

- The adsorption isotherm only depends on the concentration suspended bacteria: $\varphi=$ $\varphi(C)$.

A discussion on these assumptions can be found in Sect. 5 .

These simplifications result into the following system of equations:

$$
\begin{aligned}
\frac{\partial C}{\partial t} & =-v \frac{\partial C}{\partial x}-r_{\mathrm{ads}}+r_{\mathrm{des}}, \\
\frac{\partial \bar{C}}{\partial t} & =r_{\mathrm{ads}}-r_{\mathrm{des}}-r_{\mathrm{fix}}, \\
\frac{\partial S}{\partial t} & =r_{\mathrm{fix}}, \\
r_{\mathrm{ads}} & =k_{\mathrm{ads}}(\varphi(C)-(\bar{C}+S))_{+}, \\
r_{\mathrm{des}} & =k_{\mathrm{des}}\left((\bar{C}-(1-\beta) \varphi(C))+(S-\beta \varphi(C))_{-}\right)_{+}, \\
r_{\mathrm{fix}} & =k_{\mathrm{fix}} \bar{C}(\beta \varphi(C)-S)_{+}, \\
\frac{\partial c^{\mathrm{fix}}}{\partial t} & =-v \frac{\partial c^{\mathrm{fix}}}{\partial x} .
\end{aligned}
$$

The initial and boundary conditions are given in Sect. 2.2. 


\subsection{Analytical Solution}

In this subsection, we describe the analytical solution for the various components: the fixation fluid and the bacteria.

\subsubsection{Fixation Fluid}

Before deriving the analytical solution for the bacteria, first the solution for the fixation fluid is derived. A solution of Eq. 35 is $c^{\text {fix }}(x-v t)$. Combining this with the initial and boundary condition gives the following solution for the fixation fluid:

$$
c^{\mathrm{fix}}(x, t)=H\left(v\left(t-T_{0}\right)-x\right),
$$

where $H: \mathbb{R} \rightarrow\{0,1\}$ represents a Heaviside function, given by

$$
H(y)= \begin{cases}1 & \text { for } y>0 \\ 0 & \text { for } y<0\end{cases}
$$

\subsubsection{Bacteria}

For the derivation of the analytical solution for the concentration of suspended, adsorbed and fixed bacteria, an extra simplification has been made: the reaction constants are infinitely large: $k_{\mathrm{ads}} \rightarrow \infty, k_{\mathrm{des}} \rightarrow \infty$ and $k_{\mathrm{fix}} \rightarrow \infty$. This simplification implies an instantaneous equilibrium. As a result, $\bar{C}$ and $S$ can be found directly as a function of $C$ :

$$
\begin{aligned}
\bar{C} & =\left(1-\beta_{0} c^{\mathrm{fix}}\right) \varphi(C), \\
S & =\max _{0 \leq \bar{t} \leq t}\left\{\beta_{0} c^{\mathrm{fix}} \varphi(C)\right\} .
\end{aligned}
$$

The total bacterial concentration $\Psi$ is defined by $\Psi:=C+\bar{C}+S$. Adding the differential equations for $C, \bar{C}$ and $S$ (Eqs. 29-31), gives the following differential equation for $\Psi$ :

$$
\frac{\partial \Psi(C)}{\partial t}=-v \frac{\partial C}{\partial x} .
$$

It is assumed that $C$ is piecewise continuously differentiable in $t$ and $x$ and that $\varphi$ and $\Psi$ are continuous functions in $C$.

Along characteristics, we have

$$
0=\frac{\mathrm{d}}{\mathrm{d} t} C(t, x(t))=C_{t}+C_{x} x^{\prime}(t)
$$

and hence

$$
x^{\prime}(t)=\frac{v}{\Psi^{\prime}(C)}
$$

where $\Psi^{\prime}(C)$ is given by

$$
\Psi^{\prime}(C)= \begin{cases}1+\varphi^{\prime}(C) & \text { if } c^{\mathrm{fix}}(x, t) \varphi(C(x, t))>\max _{0 \leq \bar{t}<t}\left\{0, c^{\mathrm{fix}}(x, \bar{t}) \varphi(C(x, \bar{t}))\right\} ; \\ 1+\left(1-\beta_{0} c^{\mathrm{fix}}\right) \varphi^{\prime}(C) & \text { else. }\end{cases}
$$

Based on the above relations, we present a sketch of the $(x-t)$-diagram in Fig. 1. 
Fig. 1 Sketch of the $(x-t)$-diagram

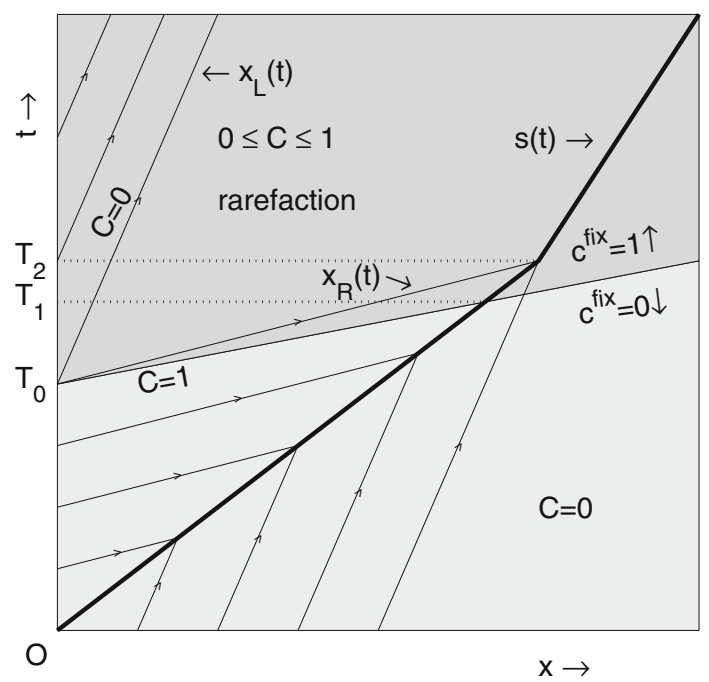

The velocity of the characteristics originating for the $x$-axis, where $C=c^{\text {fix }}=0$, is calculated with Eqs. 42 and 43:

$$
x^{\prime}(t)=\frac{v}{\Psi^{\prime}(0)}=\frac{v}{1+\varphi^{\prime}(0)} .
$$

For the characteristics, originating from the $t$-axis, we distinguish between $0<t<T_{0}$ and $t>T_{0}$. For $0<t<T_{0}$, since $C=1$ at the inflow boundary, the following expression is found for the velocity of the characteristics, originating from the $t$-axis:

$$
x^{\prime}(t)=\frac{v}{\Psi^{\prime}(1)}=\frac{v}{1+\left(1-\beta_{0} c^{\mathrm{fix}}\right) \varphi^{\prime}(1)} .
$$

Note that the velocity of the suspended bacteria changes, when they are overtaken by the fixation fluid. The characteristic of the front of the fixation fluid starts in $\left(0, T_{0}\right)$. Below this characteristic, we have $c^{\text {fix }}=0$ and therefore $x^{\prime}(t)=\frac{v}{1+\varphi^{\prime}(1)}$. Above this characteristic, we have $c^{\text {fix }}=1$ and $x^{\prime}(t)=\frac{v}{1+\left(1-\beta_{0}\right) \varphi^{\prime}(1)}$.

For $t>T_{0}$, since $C=0$ and $c^{\text {fix }}=1$ at the inflow boundary, the velocity of the characteristics is given by:

$$
x^{\prime}(t)=\frac{v}{\Psi^{\prime}(0)}=\frac{v}{1+\left(1-\beta_{0}\right) \varphi^{\prime}(0)} .
$$

The characteristics from $\left(0, T_{0}\right)$ have a lower velocity than the characteristics originating from the $x$-axis. This is a result of the retardation effect due to adsorption and this lower velocity results into a shock. The shock position is denoted by $s(t)$. Let $t=T_{1}$ be the time at which the front of the fixation fluid reaches the front of the pulse with bacteria. For $0<t<T_{1}$, the shock speed $s^{\prime}(t)$ is determined by the Rankine-Hugoniot condition (where $[\cdot]$ means the jump over the quantity):

$$
s^{\prime}(t)=\frac{[v C]}{[\Psi(C)]}=\frac{[v C]}{\left[C+\left(1-\beta_{0} c^{\mathrm{fix}}\right) \varphi(C)\right]}=\frac{v}{1+\varphi(1)}<v .
$$


Since $s(0)=0$, for $0<t<T_{1}$ the shock position is given by

$$
s(t)=\frac{v t}{1+\varphi(1)} .
$$

From the intersection of the shock position with the position of the fixation fluid front, $T_{1}$ can be found: $\frac{v T_{1}}{1+\varphi(1)}=v\left(T_{1}-T_{0}\right)$. Hence,

$$
T_{1}=\frac{1+\varphi(1)}{\varphi(1)} T_{0}
$$

Since $\varphi(1)$ is positive, we have that $T_{1}>T_{0}$.

Let $t=T_{2}$ be the time at which the shock speed changes. This change is a consequence of the decrease of $C(s(t), t)$. For $T_{1}<t<T_{2}$, the shock speed is given by

$$
s^{\prime}(t)=\frac{[v C]}{[\Psi(C)]}=\frac{[v C]}{\left[C+\left(1-\beta_{0} c^{\mathrm{fix}}\right) \varphi(C)+\max _{0 \leq \bar{t} \leq t}\left\{\beta_{0} c^{\mathrm{fix}} \varphi(C)\right\}\right.}=\frac{v}{1+\varphi(1)} .
$$

For $T_{1}<t<T_{2}$, the same shock speed has been found as for $0<t<T_{1}$, as can be seen from Eqs. 47 and 50. While deriving the model for the placement of bacteria, this turned out to be very important, since a change in the shock speed at $t=T_{1}$ turned out to lead to a violation of the conservation of mass requirement. Here, the development of the analytical solution, though for a simplified case, turned out to be very helpful to the actual construction of the model.

For $0<t<T_{2}$ the shock position is given by

$$
s(t)=\frac{v t}{1+\varphi(1)} .
$$

At $t=T_{0}$, the boundary condition changes. This gives a rarefaction wave, which is illustrated in the $(x-t)$-diagram. To this extent, we use the Ansatz $C(t, x)=\tilde{C}(\eta), \eta=\frac{x}{v\left(t-T_{0}\right)}$. This gives the following derivatives:

$$
\left\{\begin{aligned}
C_{t} & =-\frac{\eta}{t-T_{0}} \tilde{C}^{\prime}(\eta), \\
C_{x} & =\frac{1}{v\left(t-T_{0}\right)} \tilde{C}^{\prime}(\eta), \\
(\Psi(C))_{t} & =-\Psi^{\prime}(\tilde{C}) \tilde{C}^{\prime}(\eta) \frac{\eta}{t-T_{0}} .
\end{aligned}\right.
$$

Substituting Eq. 52 in relation (40) gives

$$
\left(-\Psi^{\prime}(\tilde{C}) \eta+1\right) \tilde{C}^{\prime}(\eta)=0 .
$$

This equation admits two states:

$$
\left\{\begin{aligned}
\text { 1) } \tilde{C}^{\prime}(\eta) & =0 \quad(\text { constant state }) \\
\text { 2) } \quad \eta & \left.=\frac{1}{\Psi^{\prime}(\tilde{C})} \quad \text { (variable state }\right)
\end{aligned}\right.
$$

The variable state implies that

$$
\Psi^{\prime}(\tilde{C})=\frac{1}{\eta} .
$$


Since $\Psi^{\prime}(\tilde{C})>0$ and $\Psi$ is a continuous function in $C$, this equation can be solved $\left(\Psi^{\prime}(\tilde{C})\right.$ is invertible). The solution is $C=\left(\Psi^{\prime}\right)^{-1}\left(\frac{1}{\eta}\right)$. The constant states are located at

$$
\frac{x_{L}(t)}{v\left(t-T_{0}\right)}=\eta_{L}=\frac{1}{\Psi^{\prime}(0)}<\frac{1}{\Psi^{\prime}(1)}=\eta_{R}=\frac{x_{R}(t)}{v\left(t-T_{0}\right)} .
$$

Time $T_{2}$ can be found from the intersection point of $s(t)$ and $x_{R}(t): \frac{v T_{2}}{1+\varphi(1)}=\frac{v\left(T_{2}-T_{0}\right)}{\Psi^{\prime}(1)}$. Solving this equation gives

$$
T_{2}=\frac{1+\varphi(1)}{1+\varphi(1)-\Psi^{\prime}(1)} T_{0}=\frac{1+\varphi(1)}{\varphi(1)-\left(1-\beta_{0}\right) \varphi^{\prime}(1)} T_{0},
$$

which has a solution $T_{2}>0$ iff $\varphi(1)>\left(1-\beta_{0}\right) \varphi^{\prime}(1)$. If $\varphi(1) \leq\left(1-\beta_{0}\right) \varphi^{\prime}(1)$, then $s(t)$ is given by Eq. 51 for $t>0$. Next, $s(t)$ is derived for $t>T_{2}$ for the case that $\varphi(1)>$ $\left(1-\beta_{0}\right) \varphi^{\prime}(1)$. The shock speed $s^{\prime}(t)$ is given by $s^{\prime}(t)=\frac{v C(t, s(t))}{\Psi(C(t, s(t)))}$. On the shock position, the solution is given by $C(t, s(t))=\left(\Psi^{\prime}\right)^{-1}\left(\frac{v\left(t-T_{0}\right)}{s(t)}\right)$. This gives the following differential equation in $s(t)$ :

$$
s^{\prime}(t)=\frac{v\left(\Psi^{\prime}\right)^{-1}\left(\frac{v\left(t-T_{0}\right)}{s(t)}\right)}{\Psi\left(\left(\Psi^{\prime}\right)^{-1}\left(\frac{v\left(t-T_{0}\right)}{s(t)}\right)\right)}, \quad s\left(T_{2}\right)=\frac{v T_{2}}{1+\varphi(1)} .
$$

Solving this differential equation gives the shock position $s(t)$ for $t>T_{2}$ for the case that $\varphi(1)>\left(1-\beta_{0}\right) \varphi^{\prime}(1)$. Summarizing, the following has been found for the shock position $s(t)$ :

$$
s(t)= \begin{cases}\frac{v t}{1+\varphi(1)} & \text { if } \varphi(1) \leq\left(1-\beta_{0}\right) \varphi^{\prime}(1) ; \quad \text { for } t>0 \\ \frac{v t}{1+\varphi(1)} & \text { if } \varphi(1)>\left(1-\beta_{0}\right) \varphi^{\prime}(1), \quad \text { for } 0<t<T_{2} ; \\ \frac{v T_{2}}{1+\varphi(1)}+\int_{T_{2}}^{t} \frac{v\left(\Psi^{\prime}\right)^{-1}\left(\frac{v\left(\bar{t}-T_{0}\right)}{s(\bar{t})}\right)}{\Psi\left(\left(\Psi^{\prime}\right)^{-1}\left(\frac{v\left(\bar{t}-T_{0}\right)}{s(t)}\right)\right)} \mathrm{d} \bar{t} & \text { if } \varphi(1)>\left(1-\beta_{0}\right) \varphi^{\prime}(1), \quad \text { for } t>T_{2} .\end{cases}
$$

Next, the solution for the concentration of suspended bacteria is constructed:

$$
C= \begin{cases}1 & \text { for }(t, x) \in\left(0, T_{0}\right) \times(0, s(t)) \cup\left(T_{0}, T_{2}\right) \times\left(x_{R}(t), s(t)\right) \\ 0 & \text { for }(t, x) \in\left(T_{0}, \infty\right) \times\left(0, x_{L}(t)\right) \cup \mathbb{R}^{+} \times(s(t), \infty) \\ \left(\Psi^{\prime}\right)^{-1}\left(\frac{v\left(t-T_{0}\right)}{x}\right) & \text { for }(t, x) \in\left(T_{0}, \infty\right) \times\left(x_{L}(t), \min \left(x_{R}(t), s(t)\right)\right)\end{cases}
$$

The concentration of adsorbed bacteria $\bar{C}$ and fixated bacteria $S$ is found, using Eqs. 38 and 39.

The preferred result is an homogeneous distribution of bacteria. To achieve this distribution, according to the present model, the following relation should hold:

$$
L \leq s\left(T_{2}\right)
$$

where $L$ is the length of the column. Substituting Eqs. 51 and 57 into relation (61) gives the following relation between the length of the column $L$ and the switch time $T_{0}$.

$$
L \leq \frac{v T_{0}}{\varphi(1)-\left(1-\beta_{0}\right) \varphi^{\prime}(1)} .
$$


The above relation (62) implies the following criterion on the switch time $T_{0}$ :

$$
T_{0} \geq \frac{\varphi(1)-\left(1-\beta_{0}\right) \varphi^{\prime}(1)}{v} L .
$$

\subsection{Case Study}

In this section, the solution, derived in the last section is applied to the Langmuir isotherm. According to Zheng and Bennett (1995), the Langmuir isotherm is given by

$$
\varphi(C)=\frac{\alpha \bar{C}_{\max } C}{1+\alpha C}
$$

where the positive constant $\alpha$ denotes the Langmuir constant and $\bar{C}_{\max }$ is the maximum adsorption capacity. Substituting Eq. 64 into relations (49) and (57) gives the following expressions in $\mathbb{R}^{+}$for $T_{1}$ and $T_{2}$ :

$$
\begin{aligned}
& T_{1}=\frac{1+\alpha+\alpha \bar{C}_{\max }}{\alpha \bar{C}_{\max }} T_{0} ; \\
& T_{2}=\frac{\frac{(1+\alpha)^{2}}{\alpha \bar{C}_{\max }}+(1+\alpha)}{\alpha+\beta_{0}} T_{0} .
\end{aligned}
$$

The following expression for $s(t)$ is derived:

$$
s(t)= \begin{cases}\frac{v t}{1+\varphi(1)} & \text { for } t<T_{2} ; \\ \frac{v(1+\alpha) T_{2}}{1+\alpha+\alpha \bar{C}_{\max }}+\int_{T_{2}}^{t} \frac{v \sqrt{\left(1-\beta_{0}\right) \alpha \bar{C}_{\max }\left(\bar{t}-T_{0}\right)}}{\sqrt{\left(1-\beta_{0}\right) \alpha \bar{C}_{\max }\left(\bar{t}-T_{0}\right)}+\alpha \bar{C}_{\max } \sqrt{s(\bar{t})-\left(\bar{t}-T_{0}\right)}} \mathrm{d} \bar{t} & \text { for } t>T_{2} .\end{cases}
$$

The constant states are located at

$$
\begin{aligned}
& x_{L}=\frac{v\left(t-T_{0}\right)}{1+\left(1-\beta_{0}\right) \alpha \bar{C}_{\max }} ; \\
& x_{R}=\frac{v\left(t-T_{0}\right)}{1+\frac{\left(1-\beta_{0}\right) \alpha \bar{C}_{\max }}{(1+\alpha)^{2}}} .
\end{aligned}
$$

The solution for the concentration of suspended bacteria is given by

$$
C= \begin{cases}1 & \text { for }(t, x) \in\left(0, T_{0}\right) \times(0, s(t)) \cup\left(T_{0}, T_{2}\right) \\ & \times\left(x_{R}(t), s(t)\right) ; \\ 0 & \text { for }(t, x) \in\left(T_{0}, \infty\right) \times\left(0, x_{L}(t)\right) \cup \mathbb{R}^{+} \times(s(t), \infty) ; \\ \frac{1}{\alpha}\left(\sqrt{\frac{\left(1-\beta_{0}\right) \alpha \bar{C}_{\max } \frac{x}{v-T_{0}}}{t-T_{0}}}-1\right) & \text { for }(t, x) \in\left(T_{0}, \infty\right) \times\left(x_{L}(t), \min \left(x_{R}(t), s(t)\right)\right) .\end{cases}
$$

Finally, the concentration adsorbed bacteria $\bar{C}$ and fixated bacteria $S$ are given by

$$
\begin{aligned}
& \bar{C}=\left(1-\beta_{0} c^{\mathrm{fix}}\right) \frac{\alpha \bar{C}_{\max } C}{1+\alpha C}, \\
& S=\max _{0 \leq \bar{t} \leq t}\left\{\beta_{0} c^{\mathrm{fix}} \frac{\alpha \bar{C}_{\max } C}{1+\alpha C}\right\} .
\end{aligned}
$$




\subsection{Numerical Methods}

The differential equations for the concentrations of bacteria and fixation fluid are solved by the standard Galerkin Finite Element Method. First, the weak formulation is derived by multiplication by a test function $\eta \in L^{2}(\Omega)$ and integration over the domain $\Omega$. As an example, the differential equation for the suspended bacteria, see Eq. 29, is taken. For the adsorption isotherm, the Langmuir isotherm, see Eq. 64, is used. This gives

$$
\int_{\Omega} \frac{\partial C}{\partial t} \eta \mathrm{d} \Omega+\int_{\Omega} v \frac{\partial C}{\partial x} \eta \mathrm{d} \Omega=\int_{\Omega}\left(-r_{\mathrm{ads}}+r_{\mathrm{des}}\right) \eta \mathrm{d} \Omega .
$$

For the time integration, an implicit scheme is used. That gives the following weak formulations for the urea concentration:

$$
\int_{\Omega} \frac{C^{n+1}-C^{n}}{\Delta t} \eta \mathrm{d} \Omega+\int_{\Omega} v \frac{\partial C^{n+1}}{\partial x} \eta \mathrm{d} \Omega=\int_{\Omega}\left(-r_{\mathrm{ads}}^{n+1}+r_{\mathrm{des}}^{n+1}\right) \eta \mathrm{d} \Omega .
$$

This equation holds for all $\eta \in L^{2}(\Omega)$, which vanish at location of the boundary where $C$ and $c^{\text {fix }}$ are prescribed explicitly, hence at $x=0$.

The Newton-Cotes quadrature rules have been used for the development of the element matrices and vectors. For this 1D case, line elements are used. Furthermore, linear basis functions are applied.

The differential equations for the various concentrations of bacteria are coupled, due to the reaction terms $r_{\text {ads }}$ (Eq. 32), $r_{\text {des }}$ (Eq. 33) and $r_{\text {fix }}$ (Eq. 34). Since these reaction rates are also nonlinear functions of the concentration suspended bacteria (because of the Langmuir isotherm in Eq. 64), Newton's method is used for the solution of the differential equations containing these reaction rates. By doing so, the three various concentrations of bacteria come together in one matrix-vector system.

This leads to two matrix-vector systems: one for the fixation fluid and one for the three various concentrations of bacteria.

The time span has been divided into equisized discrete time steps. First, the differential equation for the concentration of fixation fluid is solved. Next, the solution to the coupled system of differential equations for the various concentrations of bacteria is computed. Some numerical results can be found in the next section.

\section{Results}

In this section, the analytical solution is visualized for some particular times and locations. For one particular time, we show the comparison between the analytical solution and numerical simulations. The length of the column $L$ has been chosen in such a way that relation (62) holds.

The solution expressed by Eqs. 70-72 is visualized in Figs. 2 and 3. These figures display the concentration of suspended, adsorbed and fixated bacteria at several times and locations. For this visualization the following values have been used: $\alpha=1, \beta_{0}=0.5, \bar{C}_{\max }=1, T_{0}=$ 0.5 and the length of the column $L=s\left(T_{2}\right)$.

The top left graph of Fig. 2 shows the concentrations at the inlet. The concentration of suspended bacteria $C$ and the concentration fixation fluid $c^{\text {fix }}$ at the inflow boundary are prescribed in boundary conditions (27) and (28). From Eqs. 64, 71 and 72 the other concentrations $(\bar{C}$ and $S)$ can be found. 

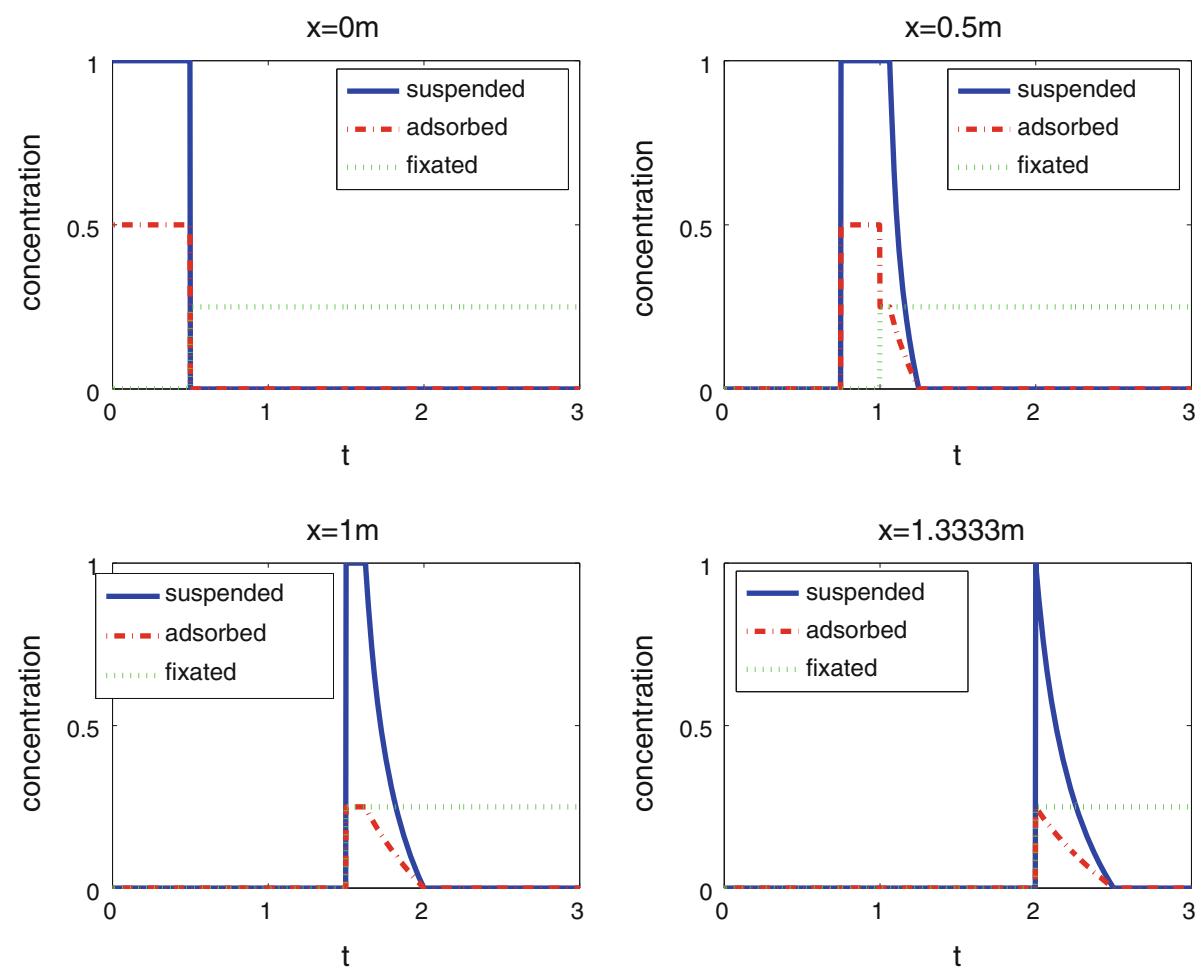

Fig. 2 The concentration of suspended, adsorbed and fixated bacteria as a function of time at $x=0,0.5$, 1 and $1.3333 \mathrm{~m}$

The top right graph of Fig. 2 shows the concentrations at $x=0.5 \mathrm{~m}$. The front of the fixation fluid starts moving at $t=T_{0}=0.5 \mathrm{~h}$, at a velocity $q=1 \mathrm{~m} / \mathrm{h}$. At $t=1 \mathrm{~h}$ the front of the fixation fluid reaches the position $x=0.5 \mathrm{~m}$. At that time and location, both suspended and temporarily adsorbed bacteria are present. A part of the temporarily adsorbed bacteria is fixated by the fixation fluid. That explains the sudden change in the concentration of temporarily adsorbed bacteria $\bar{C}$. This is also in accordance with Eq. 71 . This equation contains the multiplication factor $\left(1-\beta_{0} c^{\mathrm{fix}}\right)$. At $t=1 \mathrm{~h}$ the concentration of fixation fluid changes from 0 into 1 at $x=0.5 \mathrm{~m}$ and consequently the multiplication factor changes from 1 into 0.5 . As a result, $\bar{C}$ changes from 0.5 into 0.25 . At $t=1 \mathrm{~h}$, the concentration of fixated bacteria $S$ changes from 0 into 0.25 . Since $C$ does not increase in time after $t=1 \mathrm{~h}, S$ does not change anymore.

At $x=1 \mathrm{~m}$, the pulse bacteria is fully overtaken by the fixation fluid. Hence, the maximum of $\bar{C}$ is 0.25 in the bottom graphs of Fig. 2. Whereas the graphs in Fig. 2 have different maxima for the concentration of temporarily adsorbed bacteria, the maximum of the concentration of fixated bacteria is the same for all the graphs. This has the following reason. When there is no fixation fluid present, the bacteria are not fixated, but as soon as there is fixation fluid present, a part of the bacteria is fixated. According to Eq. 72, the maximum depends on the maximum of $C$, which is in all cases equal to 1 . The bottom right graph of Fig. 2 shows the concentrations at the outflow boundary.

The top left graph of Fig. 3 shows the initial situation: all concentrations are equal to 0 as prescribed in equation (26). The top right graph of Fig. 3 shows the situation in which the 

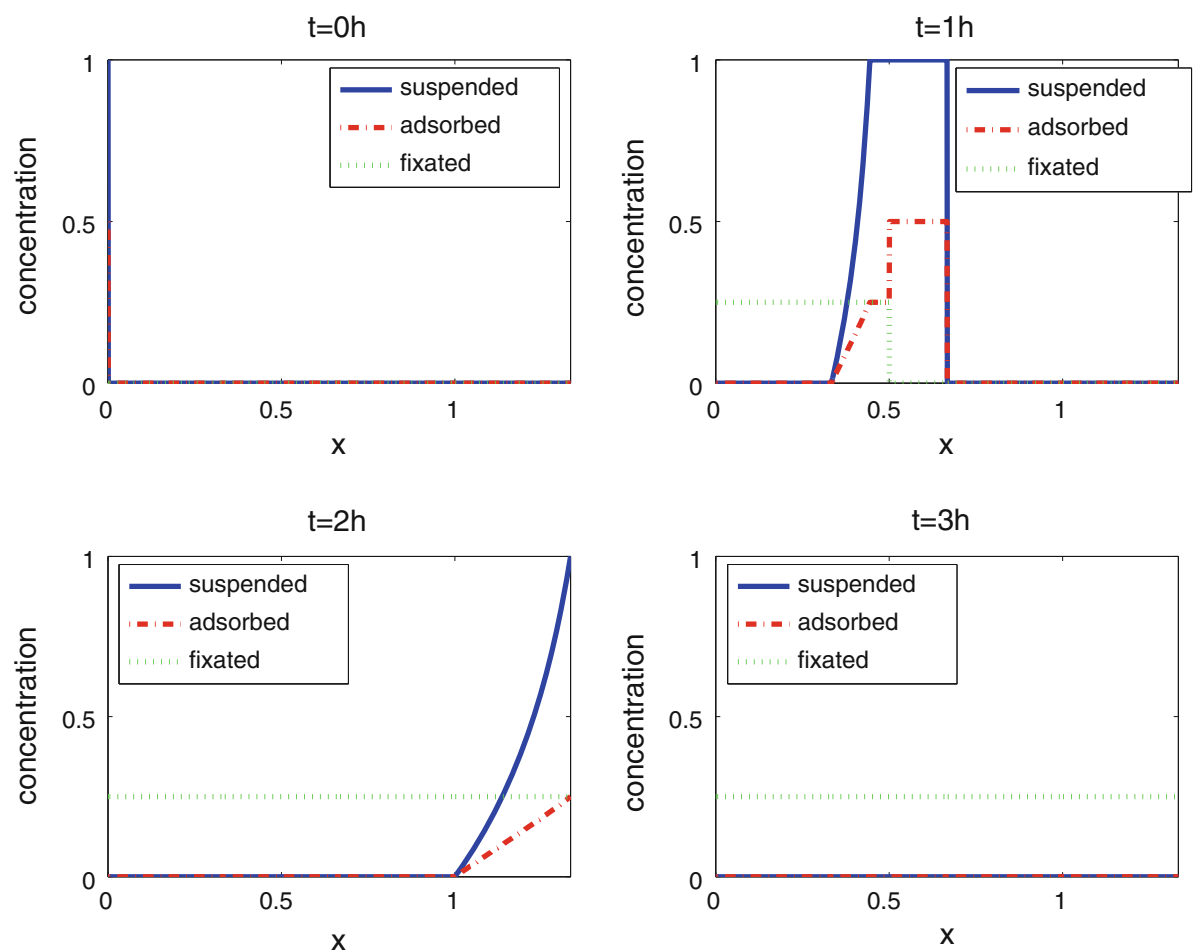

Fig. 3 The concentration of suspended, adsorbed and fixated bacteria as a function of location at several times

pulse bacteria is partly overtaken by the fixation fluid. At $t=1 \mathrm{~h}$ the front of the fixation fluid is located at $x=0.5 \mathrm{~m}$. The fixation fluid causes a sudden change in the concentration of temporarily adsorbed bacteria as was also observed in Fig. 2.

At $t=2 \mathrm{~h}$ the front of the bacterial pulse reaches the outflow boundary as is displayed in the bottom left graph of Fig. 3. The bottom right graph of Fig. 3 shows the final situation: all non-fixated bacteria are flushed out and only the permanently adsorbed bacteria stay in the domain, which will provide the hydrolysis of urea.

As a result of the conservation of bacteria, at each time, the number of bacteria in the domain must be equal to the number of bacteria that flowed in minus the bacteria that flowed out:

$$
\int_{0}^{t} q C_{\text {in }} \mathrm{d} \bar{t}-\int_{0}^{t} q C_{\text {out }} \mathrm{d} \bar{t}=\int_{\Omega}(C+\bar{C}+S) \mathrm{d} \Omega,
$$

where $C_{\text {in }}$ is the inflow concentration and $C_{\text {out }}$ is the concentration at the outflow boundary. This condition holds, as is required.

Furthermore, the analytical solution is compared to the results of the numerical simulations. This is presented for one particular time: $t=1 \mathrm{~h}$, but note that this could have been done for any other time. The numerical simulations have been done for several values of the reaction constants $k_{\mathrm{ads}}, k_{\mathrm{des}}$ and $k_{\mathrm{fix}}$. Figure 4 shows the results of this comparison. As a value for the reaction constants we use the following exemplary values: $K:=k_{\text {ads }}=$ $k_{\mathrm{des}}=k_{\mathrm{fix}}=0.01 \mathrm{~s}^{-1}\left(=36 \mathrm{~h}^{-1}\right), K:=k_{\mathrm{ads}}=k_{\mathrm{des}}=k_{\mathrm{fix}}=0.1 \mathrm{~s}^{-1}\left(=360 \mathrm{~h}^{-1}\right)$, 

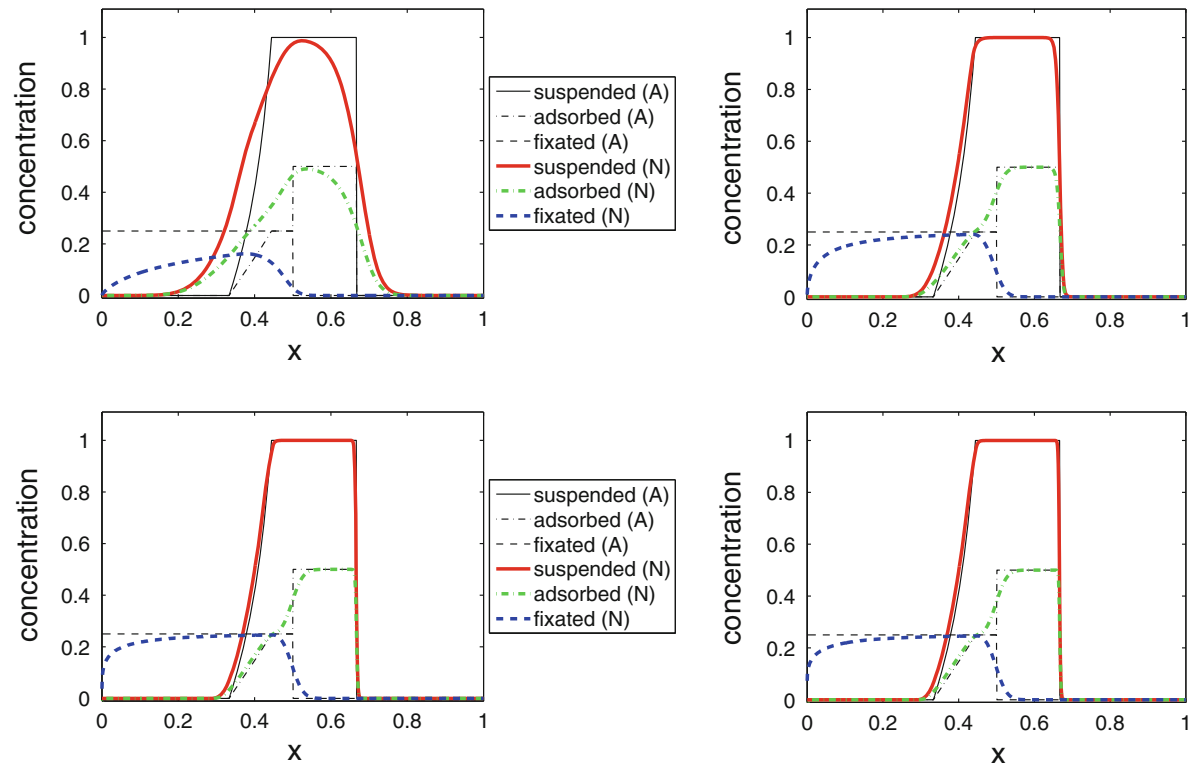

Fig. 4 Comparison of the analytical solution $(A)$ at $\mathrm{t}=1 \mathrm{~h}$ with the solutions from numerical simulations $(N)$ for several values of the adsorption, desorption and fixation constant $\left(K=k_{\mathrm{ads}}=k_{\mathrm{des}}=k_{\mathrm{fix}}\right)$. The following values have been assigned to the constants: $K=0.01 \mathrm{~s}^{-1}$ (top left), $K=0.1 \mathrm{~s}^{-1}$ (top right), $K=1 \mathrm{~s}^{-1}$ (bottom left), $K=10 \mathrm{~s}^{-1}$ (bottom right). The graphs of the analytical solutions are marked with $A$ and the graphs of the numerical solutions are marked with $N$

$\left.K:=k_{\mathrm{ads}}=k_{\mathrm{des}}=k_{\mathrm{fix}}=1 \mathrm{~s}^{-1}=3,600 \mathrm{~h}^{-1}\right)$ and $K:=k_{\mathrm{ads}}=k_{\mathrm{des}}=k_{\mathrm{fix}}=10 \mathrm{~s}^{-1}(=$ $\left.36,000 \mathrm{~h}^{-1}\right)$. The following time step and element size have been chosen: $\Delta x=0.001 \mathrm{~m}$, $\Delta t=0.001 \mathrm{~h}$.

From Fig. 4 it can be seen that, upon increasing the reaction constants, the numerical solution approaches the analytical solution. There is hardly any difference between the graph for $K=1 \mathrm{~s}^{-1}$ and the graph for $K=10 \mathrm{~s}^{-1}$ in Fig. 4 .

Figure 5 shows the results of spatial and temporal refinement. The time and place steps have been decreased two times by a factor of 2 . It follows that in most cases the numerical solution approaches the analytical solution even more for smaller time and place steps, although it is not necessarily a result of refining. Each step of refining should result into a better approximation of the exact solution and in the limit, the numerical solution will equal the exact solution with given reaction rate constants. Note that in this case the exact solution is not the analytical (instantaneous) solution but the solution to the model with finite reaction rates, with $K=10 \mathrm{~s}^{-1}$ as a reaction constant. Therefore, the numerical solution with $K=10 \mathrm{~s}^{-1}$ will not converge to the analytical solution, presented in this article for instantaneous reactions, as $\Delta t$ and $\Delta x$ tend to zero.

\section{Discussion and Conclusions}

A model has been derived for the placement of bacteria. The model contains the most important phenomena of the transport of bacteria: advection, dispersion, adsorption, desorption and fixation. Of course, other phenomena can be added, like decay, growth and systematic motion of bacteria. 

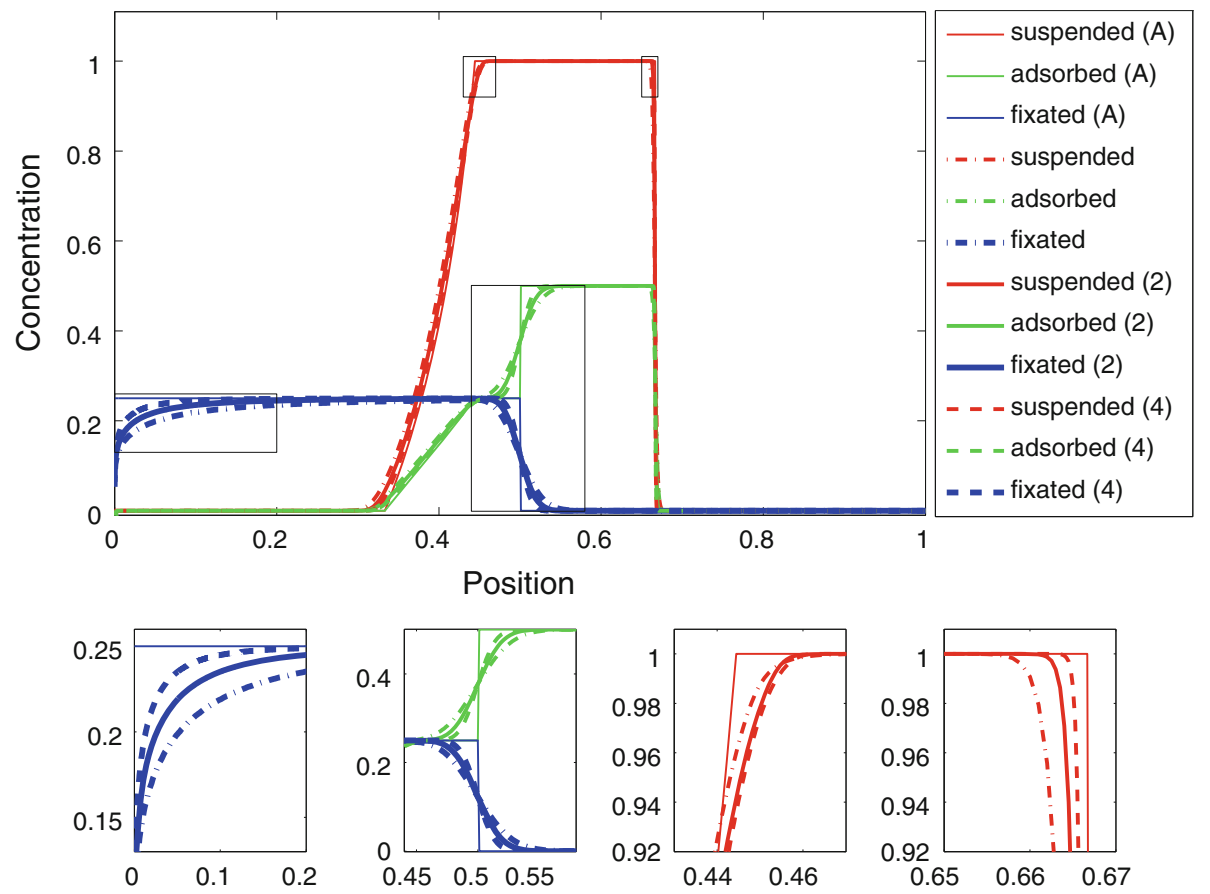

Fig. 5 Comparison of the analytical solution at $t=1 \mathrm{~h}$ with the numerical solution for decreasing time and place steps. Some details of the graph in the large subplot are given in the four subplots below. The number between brackets is the refinement factor. Again, the analytical solutions are marked with $A$. In the numerical solutions, the reaction constant has been chosen to be $K=10 \mathrm{~s}^{-1}$

The model needs to be simplified to be able to construct an analytical solution. The analytical solution is only valid in $1 \mathrm{D}$ and can be used in cases in which there are variations in only one direction. Further, the pore water velocity and the porosity have been chosen to be constant. While deriving this model, it turned out that the shock speed needs to be constant until time $T_{2}$ to avoid violation of conservation of mass. To avoid unphysical behaviour, the desorption, adsorption and fixation rate should be chosen carefully from a mathematical point of view.

This choice to simplify has been made to avoid a complex model, including a complicated coupling between the differential equation for the concentration of suspended bacteria, the pore water velocity and the porosity. However, since bacteria are fixated, the porosity decreases and that will result into a somewhat larger pore water velocity. The pore water velocity, in turn, influences the concentration of suspended bacteria. The influence of these effects depends on the volume of fixated bacteria. If this volume is not too large, this simplification will only lead to a small error. However, if the pores are almost fully filled with bacteria, this effect really should be taken into account. Although it is difficult (if ever possible) to find an analytical solution for the case that these differential equations are coupled, it is possible to find a numerical solution. Van Wijngaarden et al. $(2010,2011)$ deal with a decreasing porosity (in these papers, due to precipitation) and its effect on the flow, and obtain a numerical solution to the system of coupled differential equations.

In the model, the pore water velocity $v$ is assumed to be a constant. Due to a decreasing porosity effect, this might differ from reality as is explained in the previous paragraph. In the 
case study, the pore water velocity has been chosen to be $v=1 \mathrm{~m} / \mathrm{h}$. The solutions can easily be adapted for other values of $v$. After replacing all $x$-values by $x / v$, the results will be the same. The question is whether this is realistic. For example, the velocity might have an influence on the adsorption, desorption and fixation. Real world experiments should be carried out to examine the effect of the velocity on the processes.

In the case study, the reaction constants are equal. The larger the reaction constant, the more this reaction dominates the other reactions. If, for example, the reaction constant of the fixation reaction is large compared to the reaction constant of the adsorption reaction, the bacteria that are being adsorbed almost immediately will be fixated. Until the equilibrium of the fixated bacteria is reached, there will be far more fixated bacteria than adsorbed bacteria. If, on the other hand, the fixation constant is small, there will be more adsorbed bacteria than fixated bacteria. The fixated bacteria will not reach its equilibrium if the pulse of bacteria is too short.

Another simplification is the ignoring of dispersion and diffusion. Due to this, the front of the bacteria and the fixation fluid is very steep. Adding dispersion and diffusion to the model will result into smoother graphs. By solving the model equations numerically, always some numerical diffusion will be introduced. The finer the mesh and the smaller the time steps, the smaller the numerical diffusion. From Fig. 5 it can be seen that the numerical solution is smoother than the analytical one (note that this is not only a result of the numerical diffusion but also of the finite reaction kinetics) and that the refinements result into a steeper front.

The ratio of the fixated bacteria $\beta$ versus the adsorbed bacteria depends on the concentration of the fixation fluid, but it may also depend on the properties of the microorganisms, the $\mathrm{pH}$ and the porous medium. Since the fixation fluid has a large influence on the fixation of the bacteria and hence on $\beta$, a simple linear relation between $\beta$ and the concentration of the fixation fluid has been chosen. However, it is likely that this ratio also depends on the flow velocity. The larger the flow velocity, probably the more bacteria are released from fixation and that will lead to a smaller $\beta$. Additional research needs to be carried out to find a good expression for this ratio. It is crucial to find a good estimation, since in the model, $\beta$ prescribes the amount of fixated bacteria, and finally these bacteria provide the production of calcium carbonate, which is the aim of the Biogrout process.

In the case study, the Langmuir isotherm has been chosen as the adsorption isotherm. Real life experiments should point out whether this is a good choice for the transport of bacteria in combination with fixation.

The last simplification, that is made in order to be able to construct an analytical solution, is that the equilibrium between suspended bacteria, adsorbed bacteria and fixated bacteria is instantaneous. Therefore, no kinetics are involved and consequently, the concentration of adsorbed bacteria $(\bar{C})$ and the concentration of fixated bacteria $(S)$ are a direct function of the concentration of suspended bacteria $(C)$. Especially when the flow velocity is low, the equilibrium reaction is fast with respect to the transport. In that case, an instantaneous equilibrium can be assumed. However, since the bacteria are injected in the soil, the flow velocity will be not very low. In that case, this simplification might be not realistic and a non instantaneous equilibrium should be considered. In Fig. 4, some results are displayed for an increasing value of the reaction constants. For a small reaction constant, the result clearly differs from the solution for an instantaneous equilibrium. The larger the reaction constants are, the more the numerical solution approaches the analytical solution, and hence, the instantaneous case.

Constructing an analytical solution contributed to the derivation of a physically consistent model. Although some simplifications might be not realistic, the analytical solution gives a good idea of what the distribution of bacteria in the aquifer looks like. The analytical solution 
can also be used as a benchmark for the numerical solution. For increasing reaction constants, the numerical solution should approximate the analytical solution. This turns out to be the case (see Fig. 4). Refinement of the place and time step results into smaller numerical errors and in most cases in a better convergence to the analytical solution. In future, the analytical solution will be compared to real life bacterial placement experiments.

Open Access This article is distributed under the terms of the Creative Commons Attribution License which permits any use, distribution, and reproduction in any medium, provided the original author(s) and source are credited.

\section{References}

Bachmeier, K.L., Williams, A.E., Warmington, J.R., Bang, S.S.: Urease activity in microbiologically-induced calcite precipitation. J. Biotechnol. 93, 171-181 (2002)

Bang, S.S., Galinata, J.K., Ramakrishnanb, V.: Calcite precipitation induced by polyurethane-immobilized Bacillus pasteurii. Enzym. Microb. Technol. 28, 404-409 (2001)

DeJong, J.T., Fritzges, M.B., Nusslein, K.: Microbially induced cementation to control sand response to undrained shear. J. Geotech. Geoenviron. Eng. 132(11), 1381-1392 (2006)

DeJong, J.T., Mortensen, B.M., Martinez, B.C., Nelson, D.C.: Bio-mediated soil improvement. Ecol. Eng. 36(2), 197-210 (2010)

Fontes, D.E., Mills, A.L., Hornberger, G.M., Herman, J.S.: Physical and chemical factors influencing transport of microorganisms through porous media. Appl. Environ. Microbiol. 57(9), 2473-2481 (1991)

Foppen, J.W.A., Schijven, J.F.: Evaluation of data from the literature on the transport and survival of Escherichia coli and thermotolerant coliforms in aquifers under saturated conditions. Water Res. 40, 401-426 (2006)

Harkes, M.P., van Paassen, L.A., Booster, J.L., Whiffin, V.S., Loosdrecht, M.C.M.: Fixation and distribution of bacterial activity in sand to induce carbonate precipitation for ground reinforcement. Ecol. Eng. 36, 112-117 (2010)

Hornberger, G.M., Mills, A.L., Herman, J.S.: Bacterial transport in porous media: evaluation of a model using laboratory observations. Water Resour. Res. 28(3), 915-923 (1992)

Ivanov, I., Chu, J.: Applications of microorganisms to geotechnical engineering for bioclogging and biocementation of soil in situ. Rev. Environ. Sci. Biotechnol. 7, 139-153 (2008)

Johnson, W.P., Blue, K.A., Logan, B.E., Arnold, R.G.: Modeling bacterial detachment during transport through porous media as a residence-time-dependent process. Water Resour. Res. 31(11), 2649-2658 (1995)

Matthess, G., Pekdeger, A.: Concepts of a survival and transport model of pathogenic bacteria and viruses in groundwater. Sci Total Environ 21, 149-159 (1981)

Matthess, G., Pekdeger, A., Schroeter, J.: Persistence and transport of bacteria and viruses in groundwater-a conceptual evaluation. J. Contam. Hydrol. 2(2), 171-188 (1988)

Nemati, M., Voordouw, G.: Modification of porous media permeability, using calcium carbonate produced enzymatically in situ. Enzym. Microb. Technol. 33, 635-642 (2003)

Tan, Y., Gannon, J.T., Baveye, P., Alexander, M.: Transport of bacteria in an aquifer sand: experiments and model simulations. Water Resour. Res. 30(12), 3243-3252 (1994)

Van der Ruyt, M., Van der Zon, W.: Biological in situ reinforcement of sand in near-shore areas. Proc. Inst. Civil Eng. Geotech. Eng. 162, 81-83 (2009)

Van der Star, W.R.L., Van Wijngaarden, W.K., Van Paassen, L.A., Van Baalen, L.R., Van Zwieten, G.: Stabilization of gravel deposits using microorganisms. In: Proceedings of the 15th European Conference on Soil Mechanics and Geotechnical Engineering, pp. 85-90 (2011)

Van Meurs, G.A., Van der Zon, W.H., Lambert, J.W.M., Van Ree, C.C.D., Whiffin, V.S., Molendijk, W.O.: The challenge to adapt soil properties. In: Thomas, H.R. (ed.) Proceedings of the 5th International Congress on Environmental Geotechnics: Opportunities, Challenges and Responsibilities for Environmental Geotechnics. Thomas Telford Ltd., Cardiff, Wales, pp. 1192-1199 (2006)

Van Paassen, L.A., Van Loosdrecht, M.C.M., Van den Eijnden, A.P., Mulder, A., Verwaal, W., Ngan-Tillard, D.J.M., Harkes, M.P., Bekendam, R.F.: Reinforcement of calcarenite room and pillar mines by microbially induced carbonate precipitation. In: EuroEngeo 2008, Escuela de Ingenieria de Obras Publicas Madrid, Madrid, pp. 1-6 (2008)

Van Paassen, L.A.: Biogrout, ground improvement by microbially induced carbonate precipitation. $\mathrm{PhD}$ thesis, Delft University of Technology, pp. 1-195 (2009) 
Van Paassen, L.A., Harkes, M.P., van Zwieten, G.A., van der Zon, W.H., van der Star, W.R.L., van Loosdrecht, M.C.M.: Scale up of BioGrout: a biological ground reinforcement method. In: Hamza, M., et al. (eds.) Proceedings of the 17th International Conference on Soil Mechanics and Geotechnical Engineering, pp. 2328-2333 (2009a)

Van Paassen, L.A., Pieron, M., Mulder, A., Van der Linden T.J.M., Van Loosdrecht, M.C.M., Ngan-Tillard, D.J.M.: Strength and deformation of biologically cemented sandstone. In: Vrkljan, I. (ed.) Proceedings of the ISRM Regional conference EUROCK 2009-Rock engineering in difficult ground conditions-Soft Rocks and Karst, pp. 405-410, Dubrovnik, Croatia, 29-31 October 2009 (2009b)

Van Paassen, L.A., Ghose, R., van der Linden, T.J.M., van der Star, W.R.L., van Loosdrecht, M.C.M.: Quantifying biomediated ground improvement by ureolysis: large-scale Biogrout experiment. J. Geotech. Geoenviron. Eng. 136(12), 1721-1728 (2010)

Van Wijngaarden, W.K., Vermolen, F.J., van Meurs, G.A.M., Vuik, C.: Modelling the new soil improvement method Biogrout: extension to 3D. In: Kreiss, G., et al. (eds.) Numerical Mathematics and Advanced Applications. Springer, Berlin, pp. 893-900 (2010)

Van Wijngaarden, W.K., Vermolen, F.J., van Meurs, G.A.M., Vuik, C.: Modelling Biogrout: a new ground improvement method based on microbial-induced carbonate precipitation. Transp. Porous Med. 87, 397$420(2011)$

Whiffin, V.S.: Microbial $\mathrm{CaCO}_{3}$ precipitation for the production of biocement. Ph.D thesis, Murdoch University, Perth, Australia, pp. 1-154 (2004)

Whiffin, V.S., van Paassen, L.A., Harkes, M.P.: Microbial carbonate precipitation as a soil improvement technique. Geomicrobiol. J. 24(5), 417-423 (2007)

Yavuz Corapcioglu, M., Haridas, A.: Transport and fate of microorganisms in porous media: a theoretical investigation. J. Hydrol. 72(1-2), 149-169 (1984)

Zheng, C., Bennett, G.D.: Applied Contaminant Transport Modeling. Van Nostrand Reinhold, New York (1995) 